\title{
Rules and Regulations
}

This section of the FEDERAL REGISTER contains regulatory documents having general applicability and legal effect, most of which are keyed to and codified in the Code of Federal Regulations, which is published under 50 titles pursuant to 44 U.S.C. 1510.

The Code of Federal Regulations is sold by the Superintendent of Documents. Prices of new books are listed in the first FEDERAL REGISTER issue of each week.

\section{DEPARTMENT OF AGRICULTURE}

\section{Animal and Plant Health Inspection Service}

\section{CFR Part 340}

[Docket No. 03-038-2]

RIN 0579-AB89

\section{Introductions of Plants Genetically Engineered To Produce Industrial Compounds}

AGENCY: Animal and Plant Health Inspection Service, USDA.

ACTION: Affirmation of interim rule as final rule.

SUMMARY: We are adopting as a final rule, without change, an interim rule that amended our regulations regarding genetically engineered organisms to require that introductions of plants genetically engineered to encode compounds for industrial use be conducted only under permit. Prior to the interim rule, such introductions could be accomplished under notification, an expedited permitting procedure. The interim rule was necessary to strengthen our regulations for introductions of this small subgroup of genetically engineered plants until such time as the issues related to these plants are fully considered in conjunction with subsequent regulatory revision.

DATES: The interim rule became effective on August 6, 2003.

FOR FURTHER INFORMATION CONTACT: Dr. John Turner, Director, Policy Division, BRS, APHIS, 4700 River Road Unit 146, Riverdale, MD 20737-1238; (301) 7348365.

\section{SUPPLEMENTARY INFORMATION:}

\section{Background}

The regulations in 7 CFR part 340, "Introduction of Organisms and Products Altered or Produced Through
Genetic Engineering Which are Plant Pests or Which There is Reason to Believe are Plant Pests" (referred to below as the regulations), govern the introduction (importation, interstate movement, or release into the environment) of any organism or product altered or produced through genetic engineering that is a plant pest or that there is reason to believe is a plant pest, or any product which contains such an organism that is unclassified and/or whose classification is unknown. The regulations refer to such organisms as "regulated articles."

With certain limited exceptions, the introduction of any regulated article is prohibited unless that introduction is authorized by a permit or, for specific classes of regulated articles, the Administrator of the Animal and Plant Health Inspection Service (APHIS) has been notified of the introduction in accordance with $\S 340.3$ of the regulations, which provides for the use, under certain circumstances, of an expedited permitting procedure called notification.

The notification option was added to the regulations in 1993 (58 FR 1704453043, Docket No. 92-156-02) in order to expedite introductions for certain types of low risk plants with which APHIS had considerable regulatory experience. Under the notification procedure, the regulated article to be introduced must be a plant, and the types of genetic modifications to the plant must meet the eligibility criteria described in $\S 340.3(\mathrm{~b})$. Development of those criteria was based upon the types of genetic modifications that APHIS had reviewed and evaluated many times over the preceding years of issuing permits.

At the time the regulations were amended to provide for the use of notification, the types of genetically engineered plants that had industrial uses were typically those in which nutritional components, such as oil content, were being engineered. Since APHIS had significant regulatory experience with the types of traits then being introduced into these plants, industrial plants were eligible for the notification option. In contrast, the notification regulations in $\S 340.3(\mathrm{~b})(4)(\mathrm{iii})$ prohibited the use of notification for introductions of plants genetically engineered to encode compounds for pharmaceutical use, thus continuing to require a permit for such introductions, because of our lack of regulatory experience and scientific familiarity with these types of introduced traits.

In 2003, we noted that a number of more recent introductions of plants engineered to produce compounds intended for industrial use had been for traits different than what we were seeing in 1993. Those more recent introductions were for non-food, nonfeed traits with which APHIS has little regulatory experience or scientific familiarity. Based on the expansion of the technology and the new non-food, non-feed uses of industrial plants being developed, we believed it to be prudent and necessary to remove the notification option for all industrials pending the completion of our ongoing review of part 340.

Therefore, in an interim rule effective and published in the Federal Register on August 6, 2003 (68 FR 46434-46436, Docket No. 03-038-1), we amended the regulations to require that introductions of plants genetically engineered to encode compounds for industrial use be conducted only under permit. For purposes of the interim rule, plants engineered to produce industrial compounds include those plants that meet the following three criteria: (1) The plants are engineered to produce compounds that are new to the plant; (2) the new compound has not been commonly used in food or feed; and (3) the new compound is being expressed for non-food, non-feed industrial uses. Industrial uses include, but are not limited to, detergent manufacturing, paper production, and mineral recovery.

Comments on the interim rule were required to be received on or before October 6, 2003. We received 12 comments by that date. The comments were from companies and organizations involved in biotechnology, an organic certification service, a university biologist, a private citizen, an association of crop production and protection companies, and associations representing food producers, processors, and manufacturers. One of the commenters voiced opposition to genetically modified plants generally, but offered no specific comments relating to the interim rule. The remaining commenters expressed their support for the interim rule, although several made specific suggestions or 
raised related issues. Those comments are discussed below.

Several commenters raised issues related to the potential for plants engineered to produce industrial compounds to contaminate or adulterate food crops. Some commenters urged APHIS to require that the introduction of such crops be conducted under conditions of 100 percent containment (e.g., in secure greenhouses) or geographic isolation to ensure that adulteration does not occur. Other commenters stated that APHIS should not allow food crops to be genetically modified to produce industrial compounds in order to eliminate the potential for the spread of transgenic pollen to sexually compatible nonmodified plants. One of these commenters further suggested that if food crops are to be used to produce industrial compounds, self-pollinating crops should be used to the maximum extent possible.

APHIS wishes to reiterate that the purpose of the interim rule was to ensure that introductions of plants engineered to produce industrial compounds will be conducted under permit rather than under notification. Although there are administrative differences between these procedures, the goal of each is to ensure that plants are confined during movement and field testing and do not persist in the environment, and both are designed to achieve high levels of safety. In addition, use of any regulated article originating from a field test as food or feed would be subject to the regulatory authority of the Food and Drug

Administration (FDA). Failure to meet any of the requirements associated with APHIS permits and notifications can lead to substantial fines, as provided in the Plant Protection Act.

One commenter agreed with the three criteria set out in the interim rule to describe plants engineered to produce industrial compounds, but suggested that food or feed plants genetically engineered to produce dietary supplements that are acceptable only in dietary supplements should also be considered industrial plants and thus ineligible for introduction using the notification option.

Plants, whether genetically engineered or not, yield a variety of compounds that are used to produce dietary supplements. If a food or feed plant naturally produces a compound used in dietary supplements, and that plant has been genetically engineered to produce more of that compound, then that plant would not be considered an industrial plant (and thus would be eligible for introduction using notification) because the first of the three criteria is that "the plants are engineered to produce compounds that are new to the plant." However, if the compound is new to the plant, has not been commonly used in food or feed, and is being expressed for non-food, non-feed industrial uses, then the plant would be considered an industrial plant under our criteria and thus eligible for introduction only under permit.

Again with respect to the three criteria, one commenter suggested that APHIS may wish to clarify those criteria regarding the circumstances under which a permit will and will not be required for field testing and to provide examples of both to assist the public and those developing industrial proteins in better understanding those

circumstances.

APHIS may, when needed, provide additional written guidance illustrating the criteria that define whether a field test qualifies for the notification procedure or if it must be conducted under permit. The agency has provided such written guidance since the implementation of the regulations in part 340 in 1987, offering additional examples that would not necessarily be appropriate for inclusion in the regulations themselves and updating or clarifying that guidance as necessary. When the notification option was added to the regulations in 1993, APHIS published a user's guide to notifications. Copies of our user's guides are available in print form and may be viewed on the Agency Web site at http:// www.aphis.usda.gov/brs.

One commenter stated that, while it may be currently necessary to require that introductions of industrial plants be conducted only under permit, over time APHIS should gain sufficient familiarity with certain industrial compounds to allow plants producing such compounds to be grown under notification procedures. The commenter urged APHIS to adopt this approach as it considers amending its regulations in 7 CFR part 340.

APHIS continually evaluates its regulations in the light of increased experience and familiarity with scientific, technical, and administrative considerations. In this or any other situation, the accumulation of experience or the availability of additional information may lead us to initiate rulemaking to update the regulations.

Another commenter, also with an eye toward future amendments to the regulations, suggested that APHIS provide for enhanced oversight for industrial plants in the areas of confinement controls, site security, and compliance verification and the use of third-party auditors, standard-setting organizations, and standard operating procedures as a quality control mechanism.

APHIS agrees that it is appropriate to take the considerations identified by the commenter into account as we continue to review our existing regulations in part 340 and develop potential amendments to those regulations.

\section{Continuing Effect of Amendment}

The preamble of the interim rule stated that our amendment to the regulations in part 340 to remove the notification options for plants genetically engineered to encode compounds for industrial use would be in effect until December 31, 2004. At the time we made that statement, and as we explained in the interim rule, it was our intent to remove the notification option for all industrials pending the completion of our ongoing review of part 340. That review, which is not yet complete, is being conducted as part of our consideration of possible amendments to the regulations to, among other things, include genetically engineered organisms that may pose a noxious weed risk and genetically engineered biological control agents.

On January 23, 2004, we published a notice in the Federal Register (69 FR 3271-3272, Docket No. 03-031-2), in which we advised the public that we intend to prepare an environmental impact statement (EIS) in connection with potential changes to the regulations regarding the importation, interstate movement, and environmental release of certain genetically engineered organisms. The notice identified potential issues and alternatives that will be studied in the EIS and requested public comment to further delineate the scope of the issues and alternatives.

We believe that it is essential that we consider the findings of the EIS as part of our review of the existing regulations in part 340, but the EIS is not yet at a stage at which we may do so. Therefore, consistent with our stated intent to remove the notification option for all industrials pending the completion of our review of part 340 , we are announcing that the current requirement that introductions of plants genetically engineered to encode compounds for industrial use be conducted only under permit will continue in effect beyond December 31, 2004 , until the completion of our review of the regulations in part 340 . We expect that our review will include the publication in the Federal Register of a proposed rule for public comment and 
the subsequent publication of a final rule.

Therefore, for the reasons given in the interim rule and in this document, we are adopting the interim rule as a final rule without change.

This action also affirms the information contained in the interim rule concerning Executive Order 12866 and the Regulatory Flexibility Act, Executive Orders 12372 and 12988, and the Paperwork Reduction Act.

Further, this action has been determined to be significant for the purposes of Executive Order 12866 and, therefore, has been reviewed by the Office of Management and Budget.

\section{List of Subjects in 7 CFR Part 340}

Administrative practice and procedure, Biotechnology, Genetic engineering, Imports, Packaging and containers, Plant diseases and pests, Transportation.

\section{PART 340-INTRODUCTION OF ORGANISMS AND PRODUCTS ALTERED OR PRODUCED THROUGH GENETIC ENGINEERING WHICH ARE PLANT PESTS OR WHICH THERE IS REASON TO BELIEVE ARE PLANT PESTS}

- Accordingly, we are adopting as a final rule, without change, the interim rule that amended 7 CFR part 340 and that was published at 68 FR 46434-46436 on August 6, 2003.

Done in Washington, DC, this 28th day of April 2005

Bill Hawks,

Under Secretary for Marketing and Regulatory Programs.

[FR Doc. 05-8860 Filed 5-3-05; 8:45 am] BILLING CODE 3410-34-P

\section{NATIONAL INDIAN GAMING COMMISSION}

\section{CFR Part 542}

RIN 3141-AA27

\section{Minimum Internal Control Standards}

AGENCY: National Indian Gaming Commission.

ACTION: Final rule.

SUMMARY: In response to the inherent risks of gaming enterprises and the resulting need for effective internal controls in Tribal gaming operations, the National Indian Gaming Commission (Commission or NIGC) first developed Minimum Internal Control Standards (MICS) for Indian gaming in 1999, and then later revised them in 2002. The Commission recognized from the outset that periodic technical adjustments and revisions would be necessary in order to keep the MICS effective in protecting Tribal gaming assets and the interests of Tribal stakeholders and the gaming public. To that end, the following final rule revisions contain certain corrections and revisions to the Commission's existing MICS, which are necessary to correct erroneous citations or references in the MICS and to clarify, improve, and update other existing MICS provisions. The purpose of these final MICS revisions is to address apparent shortcomings in the MICS and various changes in Tribal gaming technology and methods. Public comment to these final MICS revisions was received by the Commission for a period of 48 days after the date of their publication in the Federal Register as a proposed rule on December 1, 2004. Thereafter, the comment period was extended for an additional 31 days until February 18, 2005.

After consideration of all received comments, the Commission has made whatever changes to the proposed revisions that it deemed appropriate and is now promulgating and publishing the final revisions to the Commission's MICS Rule, 25 CFR part 542.

DATES: Effective Date: May 4, 2005.

Compliance Date: On or before July 5 , 2005, the Tribal gaming regulatory authority shall: (1) In accordance with the Tribal gaming ordinance, establish and implement Tribal internal control standards that shall provide a level of control that equals or exceeds the revised standards set forth herein; and (2) establish a deadline no later than September 1, 2005, by which a gaming operation must come into compliance with the Tribal internal control standards. However, the Tribal gaming regulatory authority may extend the deadline by an additional 60 days if written notice is provided to the Commission no later than September 1, 2005. Such notification must cite the specific revisions to which the extension pertains.

\section{FOR FURTHER INFORMATION CONTACT:}

Vice-Chairman Nelson Westrin, (202)

632-7003 (not a toll-free number).

\section{SUPPLEMENTARY INFORMATION:}

\section{Background}

On January 5, 1999, the Commission first published its Minimum Internal Control Standards (MICS) as a Final Rule. As gaming Tribes and the Commission gained practical experience applying the MICS, it became apparent that some of the standards required clarification or modification to operate as the Commission had intended and to accommodate changes and advances that had occurred over the years in Tribal gaming technology and methods. Consequently, the Commission, working with an Advisory Committee composed of Commission and Tribal representatives, published the new final revised MICS rule on June 27, 2002. As the result of the practical experience of the Commission and Tribes working with the newly revised MICS, it has once again become apparent that additional corrections, clarifications, and modifications are needed to ensure that the MICS continue to operate as the Commission intended. To identify which of the current MICS need correction, clarification or modification, the Commission initially solicited input and guidance from NIGC employees, who have extensive gaming regulatory expertise and experience and work closely with Tribal gaming regulators in monitoring the implementation, operation, and effect of the MICS in Tribal gaming operations. The resulting input from NIGC staff convinced the Commission that the MICS require continuing review and prompt revision on an ongoing basis to keep them effective and up-to-date. To address this need, the Commission decided to establish a Standing MICS Advisory Committee to assist it in both identifying and developing necessary MICS revisions and revisions on an ongoing basis. In recognition of its government-to-government relationship with Tribes and related commitment to meaningful Tribal consultation, the Commission requested gaming Tribes, in January 2004, for nominations of Tribal representatives to serve on its Standing MICS Advisory Committee. From the 27 Tribal nominations that it received, the Commission selected 9 Tribal representatives in March 2004 to serve on the Committee. The Commission's Tribal Committee member selections were based on several factors, including the regulatory experience and background of the individuals nominated, the size(s) of their affiliated Tribal gaming operation(s), the types of games played at their affiliated Tribal gaming operation(s), and the areas of the country in which their affiliated Tribal gaming operation(s) are located. The selection process was very difficult, because numerous highly qualified Tribal representatives were nominated to serve on this important Committee.

As expected, the benefit of including Tribal representatives on the Committee, who work daily with the MICS, has proved to be invaluable. 